\title{
Addressing racial inequalities in dental education: decolonising the dental curricula
}

\author{
Kamran Ali, ${ }^{\star 1}$ Ewen McColl, ${ }^{2}$ Christopher Tredwin, ${ }^{3}$ Sally Hanks, ${ }^{3}$ Catherine Coelho ${ }^{1}$ and Robert Witton ${ }^{4}$
}

\section{Key points}

Explains 'decolonisation of the curriculum' in higher education with an emphasis on undergraduate dental curricula.
Highlights the challenges faced by minority ethnic students in healthcare education.
Provides a rationale and recommendations for decolonisation of dental curricula in UK dental schools.

\begin{abstract}
The aim of this paper is to highlight the impact of racial disparities on the educational experiences of Black and minority ethnic students in healthcare education. Attainment gaps and barriers to career progression for minority ethnic home students in the United Kingdom have been recognised for decades, but little progress has been made to address these issues. Students and staff in higher education have been campaigning for 'decolonisation of the curriculum' to improve inclusivity and representation. These trends are being mirrored in medical education and there is growing recognition to decolonise the medical curricula. This would improve the educational experience and attainment of minority ethnic students and doctors, and would also help to address disparities in healthcare provision for minority ethnic patients. The context for decolonisation of the dental curricula is provided, followed by a discussion on the benefits, challenges and strategies for such decolonisation.
\end{abstract}

\section{Introduction}

What is decolonisation of an educational curriculum?

'Decolonisation' may be defined as the process in which a country that was previously a colony (controlled by another country) becomes politically independent. ${ }^{1}$ Dismantlement of the colonial powers was started following the culmination of World War II, but withdrawal of colonial powers from a geographic space does not fully encompass the manifestations of colonialism. It warrants a change of a mindset which legitimises dominance of racial supremacy and portrays the colonised as 'inferior.' Although colonialism of countries

'University of Plymouth, Peninsula Dental School, C504 Portland Square, Plymouth, Devon, PL4 8AA, UK; 2University of Plymouth, UK; ${ }^{3}$ University of Plymouth, Peninsula Dental School, The John Bull Building, Plymouth Science Park, Plymouth, Devon, PL6 8BU, UK; “Plymouth University Schools of Medicine and Dentistry, Social Engagement and Community-Based Dentistry, The John Bull Building, Plymouth Science Park, Plymouth, Devon, PL6 8BU, UK.

*Correspondence to: Kamran Ali

Email address: kamran.ali@plymouth.ac.uk

Refereed Paper.

Accepted 16 October 2020

https://doi.org/10.1038/s41415-020-2598-z is considered to be a relic of the past, the higher education curricula continue to be colonised by white and Western intellectual traditions, and lack appropriate representation of Black and minority ethnic groups.

While there is no single, universally accepted definition of 'decolonisation of the curriculum', the term is used to describe: 'Creation of spaces and resources for a dialogue among all members of the university on how to imagine and envision all cultures and knowledge systems in the curriculum, and with respect to what is being taught and how it frames the world. ${ }^{3}$ Such discourse requires deconstruction, rethinking and reconstruction in order to make curricula inclusive and representative of different communities, voices and perspectives. A contextual approach to curriculum design and delivery may allow universities to evaluate how curriculum and therefore education - influences social relations, practices and culture. ${ }^{4}$

Decolonisation of higher education curricula started as a movement at the University of Cape Town to remove influences of colonialism and provide representation of the knowledge and perspectives of indigenous people. It was a student-led initiative that advocated for the removal of the statue of Cecil John Rhodes from the university's campus and later became known as the Rhodes Must Fall movement ${ }^{5}$ The campaign challenged the Eurocentric hierarchies of race, social class and gender in South Africa. Since then, this movement spread further afield and was replicated in the United Kingdom (UK) with Oxford's Rhodes Must Fall campaign. Student bodies and staff in UK universities are actively campaigning for decolonising curricula in higher education institutions. Student unions at leading universities including Oxford, Cambridge, London, Kent, Leeds and many more are already part of this movement. ${ }^{6}$

Although implicit, colonial influences still persist in universities and shape our assumptions about how society needs to work, what needs to be taught and how it needs to be taught. The power relations and hierarchical structures in educational institutions may give disproportionate importance to the opinions, experiences and achievements of white men. However, it is time to investigate and challenge these assumptions so that we can build an education culture where every human being has an equal right to contribute to and influence creation of knowledge. 
A critical part of decolonisation of the curriculum is to revisit the reading lists by considering how the location of authors shape their narratives and perspectives. ${ }^{3}$ The aim is to diversify the learning resources for students, bring in new perspectives and make the reading lists more representative, rather than being restricted to view all information through the lens of Eurocentric authors. Students and researchers should be encouraged to read literature from diverse sources. Similarly, publishers need to engage with writers and scholars from non-white backgrounds to develop a new generation of authors representative of their readers. Librarians and information specialists can also play an important role in supporting their institutions by reviewing the reading list as they are responsible for organising, coding and retrieval of knowledge, and can provide useful insights into how it may impact on minority ethnic groups. ${ }^{6}$

While this conversation can be a difficult one, students understandably expect this matter to be addressed as a priority. Sociopolitical discourse on racial inequalities also needs to be viewed in the context of attainment gaps among minority ethnic students in higher education. ${ }^{7,9}$ The debate has intensified in the backdrop of recent events related to the death of George Floyd in the USA and the subsequent spiralling of the Black Lives Matter movement. Given the growing population of minority ethnic students in UK universities, debates on racism are likely to get stronger in the future.

\section{Implications of racial inequalities in healthcare education}

Racial inequalities in healthcare education and practice are multifaceted and, despite substantial evidence of disparities in health outcomes for minority ethnicities and differential attainment among students and staff, minimal progress has been made to address these issues. ${ }^{10}$ Racial inequalities in healthcare are also linked to poorer experiences of patients from minority ethnic backgrounds and even an increased risk of certain diseases. ${ }^{11,12,13}$ These disparities have been further highlighted in the recent COVID-19 crisis by Public Health England due to the disproportionate effects of COVID19 on minority ethnic patients and healthcare professionals. ${ }^{14}$

The educational experiences, attainment and working lives of minority ethnic students and staff in UK healthcare professions are also a source of concern. Data from programmes in medicine show that minority ethnic undergraduate medical students and doctors in the UK are more likely to fail assessments than their white counterparts. ${ }^{15,16} \mathrm{UK}$ medical graduates from minority ethnic backgrounds are also less likely to be shortlisted and selected for speciality training programmes. ${ }^{17}$ In addition, less favourable outcomes for minority ethnic doctors are reported regarding successful applications for consultant posts in the NHS and subsequent pay gaps compared to their white peers. Similar findings have been reported for minority ethnic nurses in the UK, with their attainment levels lower than White British students and with a higher likelihood of facing discrimination. ${ }^{18,19}$

Data on performance and attainment of minority ethnic students in dentistry do not appear to be available widely in the public domain, but disparities have been highlighted in admissions to dental undergraduate programmes. ${ }^{20}$ Although reliable inferences regarding minority ethnic students in dentistry cannot be made in the absence of such data, it is unlikely that the trends in dentistry would be markedly different from those in medicine.

Attainment gaps among students and healthcare professionals from minority ethnic backgrounds are largely related to social factors and stereotyping. ${ }^{21}$ However, the influences of medical curricula on health inequalities and attainment gaps among minority ethnic students have not been researched adequately. ${ }^{22}$ It is also important that the minority ethnic students in healthcare education see themselves represented in the curriculum and do not feel obliged to study a 'white' curriculum which does not represent the healthcare needs of an increasingly diverse society.

\section{Decolonisation of the dental curricula}

Like other healthcare professions, dentistry has a historical legacy of being conceptualised as a 'white' profession..$^{23}$ Despite a growing population of students in higher education including medicine and dentistry, there are stark ethnic disparities in UK academic employment and approximately $76 \%$ of academic faculty and staff members identified as white, $9 \%$ as Asian and $2 \%$ as Black. ${ }^{24}$ This is also reflected in the low proportion of minority ethnic dental academics in senior posts in UK dental schools. ${ }^{25}$
Ethnic disparities in turn may influence the power relations and academic hierarchies in dental schools and pose an impediment to proportional representation of minority ethnic staff and students in institutional strategy and decision-making processes. Data from medical schools also highlight that students tend to accept that career progression may be dependent on their capacity to tolerate intimidation and they may not feel confident in questioning the underlying power relations and rules of engagement. ${ }^{26}$ Studies also show that minority ethnic medical students are more likely to experience bullying and harassment. ${ }^{27}$ There is insufficient research on experiences of minority ethnic dental students in the UK, which only adds to these concerns. ${ }^{28}$

Decolonisation of dental curricula needs to be considered in a psychosocial context. Racial inequalities in dental education have a negative impact on the educational experiences of students from minority ethnic groups and may contribute to poor educational experiences and attainment gaps, and pose barriers to career progression. Lack of representation of minority ethnic groups in dental curricula can also translate into disparities in patient care for minority ethnic groups, with far-reaching implications for their health and wellbeing. If dental schools are to make meaningful progress on decolonisation of curricula, it would require: a systematic review of the existing governance structure; appropriate representation and empowerment of minority ethnic staff and students in existing committee memberships; and treating decolonisation as a strategic priority. ${ }^{29}$

Decolonisation of the dental curricula is also fundamental to improve the cultural competence of dental graduates and warrants a review of curriculum content and delivery, provision of dental care in community settings and promotion of reflective practices. ${ }^{30}$ The focus of these measures should be to improve the skills of students to provide dental care to diverse population groups and improve patient experiences. Prevalence of dental disease is higher while patient satisfaction rates and access to dental treatment are lower among minority ethnic populations in the UK. ${ }^{31} \mathrm{~A}$ recent randomised clinical trial showed that dental clinicians were more likely to recommend root canal treatment for white patients $(86.21 \%)$ compared to Black patients $(60.71 \%)$ for the management of a carious molar. Dentists were far more likely to recommend extraction in the Black patient 
group. ${ }^{32}$ Two separate systematic reviews in medicine also concluded that many physicians, regardless of speciality, demonstrate an implicit preference for white people. ${ }^{33,34}$ The General Dental Council's (GDC's) Standards for the dental team mandates all professionals to treat all patients equally and without discrimination. ${ }^{35}$ Dental institutions across the country now provide staff training on equality, diversity and managing unconscious bias. These are welcome steps, but there is also a need for regular clinical audits to investigate the impact of implicit racial bias in clinical decision-making by students and staff, for selfreflection and to monitor compliance.

With regards to curriculum content of biomedical sciences, dental educators also need to address the interplay between race and disease. Racial background and skin colour of patients can have a remarkable impact on the prevalence and clinical presentation of disease, and can in turn impact on the diagnosis and subsequent management by healthcare professionals.

The classical signs and symptoms of recognised medical conditions may be difficult to detect in minority ethnic individuals if the teaching predominantly relates to white patients, which may impact adversely on timely management of individuals who do not seem to conform to the perceived norm. For example, cyanosis detection on black skin requires 3-6\% more arterial oxygen desaturation. ${ }^{36}$ Similarly, skin and mucosal pallor, rashes, erythema, ecchymosis, petechial haemorrhages and purpura may appear to be quite different and often less remarkable in Black patients. Without appropriate training, clinicians may struggle to identify these signs efficiently in patients with dark skin, especially during medical emergencies. Conditions associated with increased melanin pigmentation may be masked in patients with dark skin. ${ }^{37}$ The normal range of laboratory tests, such as renal function tests, may also be different for Black individuals and these differences need to be accounted for when interpreting the results.

Additionally, individuals with dark skin may show several variations, including racial melanin pigmentation of the oral mucosa. ${ }^{38}$ Another example is leukoedema which is prevalent in Black individuals. It is characterised by diffuse greyish-white discolouration of the buccal mucosae bilaterally and may be misinterpreted as leukoplakia. ${ }^{39}$

Moreover, dental curricula do not place sufficient emphasis on skin cancer in Black patients. While basal cell carcinoma is the most common skin cancer in white patients and affects sun-exposed areas of skin, squamous cell carcinoma is more common in the Black population..$^{30}$ Similarly, melanoma in Black and Asian patients most commonly occurs on non-exposed areas of skin and shows several variations compared to white patients, which may lead to delayed diagnosis and poor survival rates. ${ }^{40,41,42}$

Ethnic background of subjects may also influence perceptions regarding ideal facial profile and aesthetics, which may have implications in orthodontics as well as orthognathic and plastic surgery. ${ }^{43}$ Anecdotally, many clinicians believe that tooth extractions are more difficult in Black patients and indeed this is also sometimes discussed in exodontia teaching in dental schools. While such claims may be true in certain cases, they warrant further research based on good-quality evidence to identify and manage perceived risks of tooth extractions in Black patients. Perhaps many more examples may be quoted, but the fundamental point is that recognition of disease in non-white individuals presents unique challenges for clinicians despite a growing minority ethnic population in the UK. Dental students may not have sufficient knowledge, learning resources and clinical exposure to recognise these differences.

\section{Discussion}

Recently, Malone Mukwende, a second-year Black medical student at St George's University of London, received extensive media coverage for highlighting challenges of interpreting signs of disease on people with black skin. ${ }^{44}$ As a Black student, Mr Mukwende felt alienated with the way in which clinical skills are taught due to the lack of discussion around clinical signs on darker skin. It is quite remarkable that it took a student to highlight this important issue which seems to have been largely ignored in medical institutions for as long as one could go. Working with academic staff, Mr Mukwende has developed a handbook entitled Mind the gap, which aims to educate students and clinicians about the differences in the presentation of diseases in people with dark skin. This story may be an eye-opener for healthcare educators as it provides a clear example of how racial background of patients has not been fully addressed in teaching and learning. It also provides a strong argument for decolonising the curricula in healthcare education. ${ }^{45}$ Calls for decolonising the medical curricula have been growing in the last few years. This trend is evidenced by the special issue of the British Medical Journal on racism in medicine which was published in February 2020. ${ }^{46}$

It is noteworthy that the voice of the dental profession is not prominent in the debate on racism. There is a paucity of published data on dental students' attainment, which warrants a more open and transparent approach to data sharing, including the differential performance based on protected characteristics of students. Data on admissions to undergraduate programmes in dentistry (1996-2011) show that the odds of applicants gaining admission were lowest for males, those of Black ethnicity and those from a lower socioeconomic classification, while Asian students and females were more likely to get admission. ${ }^{20}$ The findings mirror data from the wider higher education sector which show the attainment gap among minority ethnic students is greater in Black than in Asian students. ${ }^{9}$ These observations highlight additional challenges for Black students which may also need to be considered.

Although decolonising of dental curricula requires a long-term strategy and sustained commitment, it deserves to be made a priority in dental schools through meaningful engagement with all stakeholders, especially students and subject experts from diverse backgrounds. Following resumption of teaching after the lockdown, students at our dental school are already contacting teaching staff to inquire what is being done to decolonise the curriculum. Therefore, there is little room for complacency, and dental institutions need to take immediate steps to identify and rectify racial disparities in dental curricula. A multi-pronged strategy to transform the educational culture with a pooling of resources and expertise can help dental schools to start this journey; some key recommendations are summarised below:

- Dental institutions should make effective use of platforms such as Health Education England (HEE), which commissions dental education in the UK, and the Dental Schools Council (DSC) to share data on student attainment and collaborate to address any gaps. In this regard, HEE and DSC could serve as central hubs to share ideas and strategies to decolonise the dental curriculum 
- The Race Equality Charter (REC) by Advance HE provides an excellent framework for higher education institutions to identify and self-reflect on institutional and cultural barriers faced by minority ethnic staff and students. ${ }^{47}$ Although signing up and submissions for the REC are done at the university level, dental schools must engage with the process proactively and use this as an opportunity to detect and address barriers to attainment and progressions for minority ethnic students. The GDC's Standards for education requires dental institutions to ensure that students are protected from all forms of discrimination, and that assessments are fair and free from bias ${ }^{48}$

- Universities in the UK have a committee structure in place to address issues of equality, diversity and inclusion, and these committees can serve as effective platforms to engage with minority ethnic students and staff. Similarly, lay members on dental committees should include minority ethnic representation. Together with student voice, public representation should be used to inform curriculum development, teaching and assessments

- The curriculum content needs to be reviewed to ensure students are trained adequately to recognise varying signs and symptoms of disease in patients from minority ethnic backgrounds, in order to enhance their cultural competence. Dental schools may need to develop bespoke learning resources and assessments to meet these goals

- Review reading lists by engaging with minority ethnic students and staff, and ensure that they are inclusive and that minorities are represented appropriately. ${ }^{49}$

\section{Conclusions}

Decolonising the curricula in healthcare education is an essential step to address racial inequalities in healthcare education and to make education more inclusive, in order to provide participation and representation to minority ethnicities. Dental schools in the UK need to actively pursue decolonisation of dental curricula by engaging with all stakeholders and adopting a shared strategy. While the conversation can - at times - be challenging, it is one that should be addressed by all in the profession to optimise educational outcomes and patient care.
Conflict of interest

None of the authors have any conflict of interest.

\section{Acknowledgements}

The authors would like to thank dental students who have volunteered as equality champions and who provide useful input into our ongoing strategy for decolonising the dental curriculum at our institution. James Nwaduba, an undergraduate student from an ethnic minority background, kindly provided a useful critique on the contents of this manuscript.

\section{References}

1. Cambridge Dictionary. Decolonization. Available at https://dictionary.cambridge.org/dictionary/english/ decolonization (accessed August 2020).

2. Jonsen, K, Maznevski, M L, Schneider S C. Gender differences in leadership - believing is seeing: implications for managing diversity. Equal Divers Inclus Int J 2010; 29: 549-572.

3. Keele University. Keele Manifesto for Decolonising the Curriculum. 2018. Available online a https://www.keele.ac.uk/equalitydiversity/ equalityawards/raceequalitycharter/ keeledecolonisingthecurriculumnetwork/ (accessed August 2020).

4. Mgqwashu E. Universities can't decolonise the curriculum without defining it first. 2016. Available at https://theconversation.com/universities-cantdecolonise-the-curriculum-without-defining-itfirst-63948 (accessed December 2020).

5. Nyamnjoh A. The phenomenology of Rhodes Must Fall: Student activism and the experience of alienation at the University of Cape Town. 2017. Available at https:// www.up.ac.za/media/shared/85/Strategic\%20Review/ Vol\%2039(1)/pp-256-277-a-nyamnjoh.zp121542.pdf (accessed December 2020).

6. Charles E. Decolonizing the curriculum. 2019. Available at https://insights.uksg.org/articles/10.1629/uksg.475/ (accessed December 2020).

7. Smith S. Exploring the black and minority ethnic (BME) student attainment gap: what did it tell us? Actions to address home BME undergraduate students' degree attainment. J Perspect Appl Acad Pract 2017; 5: 48-57.

8. Richardson J T. Understanding the under-attainment of ethnic minority students in UK higher education: The known knowns and the known unknowns. In Arday J, Mirza H S (eds) Dismantling Race in Higher Education. pp 87-102. Cham: Palgrave Macmillan, 2018.

9. Richardson JT. The under-attainment of ethnic minority students in UK higher education: what we know and what we don't know. J Furth High Educ 2015; 39: 278-291.

10. Kmietowicz Z, Ladher N, Rao M, Salway S, Abbasi K, Adebowale V. Ethnic minority staff and patients: a health service failure. BMJ 2019; DOI: 10.1136/bmj. 12226.

11. Public Health England. Local action on health inequalities: Understanding and reducing ethnic inequalities in health. 2018. Available at https:// assets.publishing.service.gov.uk/government/uploads/ system/uploads/attachment_data/file/730917/ local_action_on_health_inequalities.pdf (accessed August 2020).

12. Pham T M, Carpenter J R, Morris T P, Sharma M, Petersen I. Ethnic differences in the prevalence of type 2 diabetes diagnoses in the UK: Cross-sectional analysis of the health improvement network primary care database. Clin Epidemiol 2019; 11: 1081-1088.

13. McKenzie K, Bhui K. Institutional racism in mental health care. BMJ 2007; 334: 649-650.

14. Kirby T. Evidence mounts on the disproportionate effect of COVID-19 on ethnic minorities. Lancet Respir Med 2020; 8: 547-548.
15. Woolf K, Potts H W W, McManus I C. Ethnicity and academic performance in UK trained doctors and medical students: systematic review and meta-analysis. BMJ 2011; DOI: 10.1136/bmj.d901.

16. Esmail A, Roberts C. Academic performance of ethnic minority candidates and discrimination in the MRCGP examinations between 2010 and 2012: analysis of data. BMJ 2013; DOI: 10.1136/bmj.f5662.

17. Shah $R$, Ahluwalia $S$. The challenges of understanding differential attainment in postgraduate medical education. BrJ Gen Pract 2019; 69: 426-427.

18. Squires $E$. What pedagogic teaching styles can be used to improve the attainment levels of black and minority ethnic student nurses? 2018. Available online at https://www.herts.ac.uk/__data/assets/pdf_ file/0007/210796/BLiP-Summer-2018.pdf (accessed December 2020)

19. Isaac D. Analysing UK equal opportunity policy and legislation: has it influenced the progression of BME nurses? 2018. Available online at https://www.gavinpublishers.com/ articles/perspective-article/InternationalJournal-of-Nursing-and-Health-Care-Research/ analysing-uk-equal-opportunity-policy-and-legislationhas-it-influenced-the-progression-of-bme-nurses (accessed December 2020).

20. Niven V, Andiappan M, Cabot L, Gallagher J E Embarking on a professional career: social advantage in dentistry and medicine. UK dental and medical student applications and admissions, 1996-2011. Br Dent J 2019; 227: 411-418

21. Exworthy M, Blane D, Marmot M. Tackling health inequalities in the United Kingdom: the progress and pitfalls of policy. Health Serv Res 2003; 38: 1905-1922.

22. Claridge H, Stone K, Ussher M. The ethnicity attainment gap among medical and biomedical science students: a qualitative study. BMC Med Educ 2018; 18: 1-2.

23. Adams T L. Combining gender, class, and race: Structuring relations in the Ontario dental profession. Gender Soc 1998; 12: 578-597.

24. Woolston C. White men still dominate in UK academic science. Nature 2020; 579: 622.

25. Dental Schools Council. Survey of Dental Clinical Academic Staffing Levels. 2018. Available at https:// www.dentalschoolscouncil.ac.uk/wp-content/ uploads/2018/08/clinical-academic-surveydental-2018. pdf (accessed October 2020).

26. Lempp H. Medical-school culture. In Brosnan C, Turner B S (eds) Handbook of the Sociology of Medical Education. pp 85-102. Abingdon: Routledge, 2009.

27. Broad J, Matheson M, Verrall $F$ et al. Discrimination, harassment and non-reporting in UK medical education. Med Educ 2018; 52: 414-426.

28. Neville P. Exploring the ethnic diversity of UK dentistry. 2018. Available online at https://www.mededpublish. org/manuscripts/1496 (accessed December 2020).

29. Forsyth C, Short S, Gilroy J, Tennant M, Irving M. An Indigenous cultural competence model for dentistry education. Br Dent J 2020; 228: 719-725.

30. Forsyth C J, Irving M J, Tennant M, Short S D, Gilroy J A. Teaching cultural competence in dental education: a systematic review and exploration of implications for indigenous populations in Australia. J Dent Educ 2017; 81: 956-968.

31. NHS Airedale, Bradford and Leeds, Bradford Teaching Hospitals NHS Foundation Trust, Bradford District Care Trust and Airedale NHS Foundation Trust. Race: Evidence of health inequalities affecting black and minority ethnic people. 2016. Available at https://www. bdct.nhs.uk/wp-content/uploads/2016/12/Race.pdf (accessed August 2020).

32. Patel N, Patel S, Cotti E, Bardini G, Mannocci F. Unconscious Racial Bias May Affect Dentists' Clinical Decisions on Tooth Restorability: A Randomized Clinical Trial. JDR Clin Trans Res 2019; 4: 19-28.

33. Dehon E, Weiss N, Jones J, Faulconer W, Hinton $E$, Sterling $S$. A systematic review of the impact of physician implicit racial bias on clinical decision making Acad Emerg Med 2017; 24: 895-904.

34. Hall W J, Chapman M V, Lee K M et al. Implicit racial/ ethnic bias among health care professionals and its influence on health care outcomes: a systematic 
review. Am J Public Health 2015; DOI: 10.2105/ AJPH.2015.302903.

35. GDC. Standards for Education: Standards and requirements for providers. 2015. Available at https:// www.gdc-uk.org/docs/default-source/qualityassurance/standards-for-education-(revised-2015).pdf (accessed August 2020)

36. Adeyinka A, Kondamudi N P. Cyanosis. 2019. Available online at https://www.ncbi.nlm.nih.gov/books/ NBK482247/ (accessed December 2020).

37. Bhushan M, Ayer G. Dermatological disorders presenting in deeply pigmented skin. Dermatol Nurs 2011; 10: 12-17.

38. Vivier D. A study of the spectrum of skin disease occurring in a black population in south-east London. $\mathrm{Br}$ J Dermatol 1999; 141: 512-517.

39. Neville B W, Damm D D, Allen C M, Bouquot J E. Oral and maxillofacial pathology. 2nd ed. Philadelphia: Saunders, 2002.

40. Gloster H M, Neal K. Skin cancer in skin of colour. J Am Acad Dermatol 2006; 55: 741-760.

41. American Cancer Society. Cancer Facts \& Figures. 2020. Available at https://www.cancer.org/content/ dam/cancer-org/research/cancer-facts-and-statistics/ annual-cancer-facts-and-figures/2020/cancer-factsand-figures-2020.pdf (accessed August 2020).

42. Bradford, Porcia T. Skin Cancer in Skin of Colour. Dermatol Nurs 2009; 21: 170-178.

43. Sutter JrRE, Turley P K. Soft tissue evaluation of contemporary Caucasian and African American female facial profiles. Angle Orthod 1998; 68: 487-496.

44. St George's University of London. Mind the Gap: A Handbook on Clinical Signs on Black and Brown Skin 2020. Available at https://www.sgul.ac.uk/news/ mind-the-gap-a-handbook-of-clinical-signs-on-blackand-brown-skin (accessed August 2020).

45. Gishen $F$, Lokugamage A. Diversifying the medical curriculum. BMJ 2019; DOI: 10.1136/bmj.I300.

46. Adebowale V, Rao M. Racism in medicine: why equality matters to everyone. BMJ 2020; DOI: 10.1136/bmj. m530.

47. Advance HE. Race Equality Charter. Available online at https://www.advance-he.ac.uk/equality-charters/raceequality-charter (accessed August 2020).

48. GDC. Standards for the Dental Team. 2013. Available at https://standards.gdc-uk.org/Assets/pdf/ Standards\%20for\%20the\%20Dental\%20Team.pdf (accessed August 2020).

49. Bird K S, Pitman L. How diverse is your reading list? Exploring issues of representation and decolonisation in the UK. Higher Educ 2020; 79: 903-920.

\section{Correction to: SARS-CoV-2:}

\section{characterisation and mitigation} of risks associated with aerosol generating procedures in dental practices

The original article can be found online at https://doi.org/10.1038/s41415-020-2504-8.

Author's correction note:

Research article $B r$ Dent $J$ 2021; DOI: 10.1038/s41415-020-2504-8.

When this article was originally published, the incorrect version of Figure 3 was displayed. The correct figure is presented here, in which the black lines continue down to $\mathrm{T}=21$ minutes on the $\mathrm{x}$-axis.

Additionally, a sentence was omitted from the first paragraph of the Discussion section. In the Discussion section, 'The use of either the HVS(IO), or the HVS(IO) combined with the ACS, was enough to reduce the fallow time to zero minutes' should have read 'The use of either the HVS(IO), or the HVS(IO) combined with the ACS, was enough to reduce the fallow time to zero minutes. Please refer to Figure 2 for fallow time and Figure 3 for zero fallow time, right of the superimposed black vertical 18-21-minute lines.'

The authors apologise for any inconvenience caused.

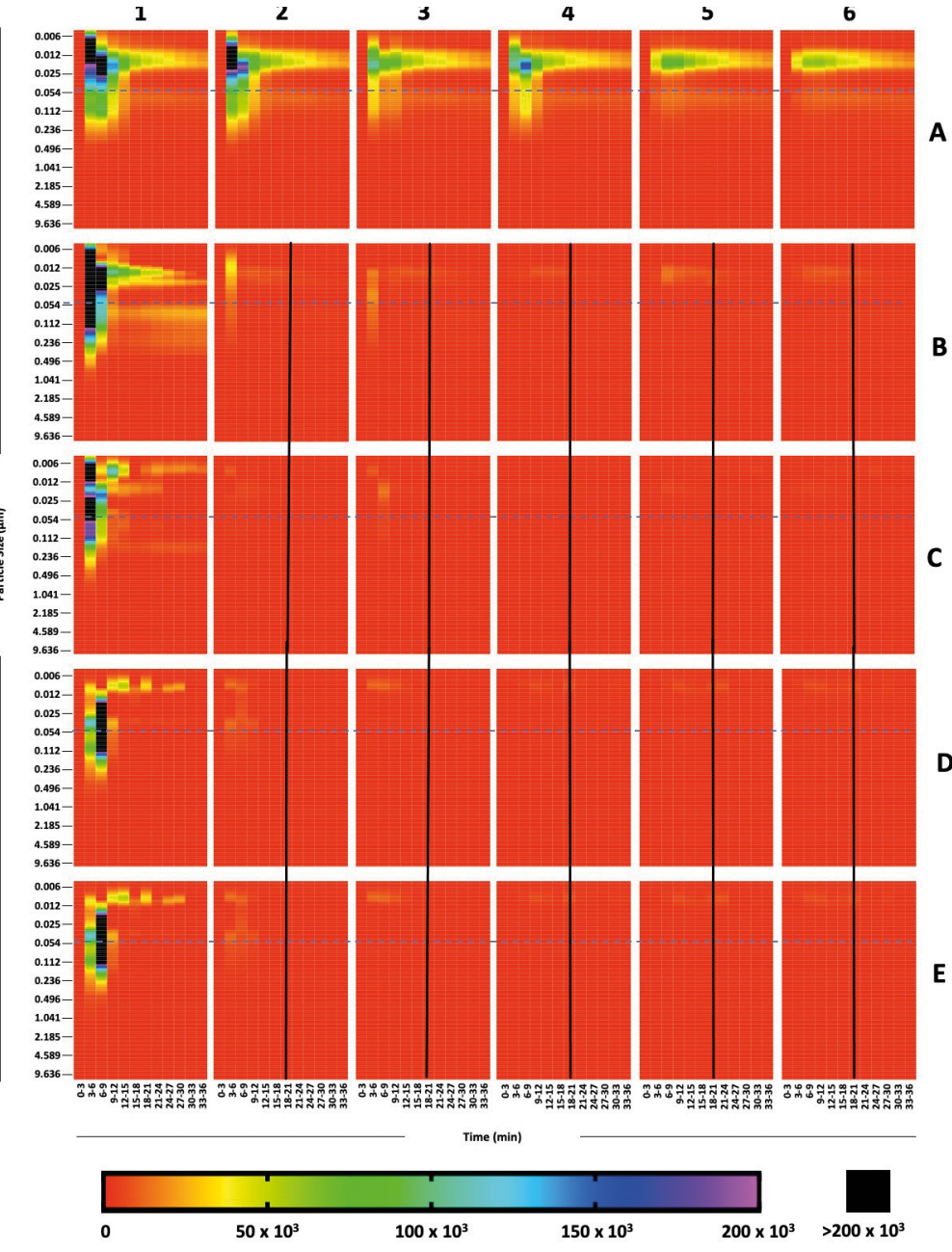

Fig. 3 Temporal, spatial and size characterisation of particles generated during AGPs (measured by HR-ELPI) for each location (1-6; Table 1) and intervention group (A-E; Table 2). Acquisition of air samples were performed during the baseline period (0-3 minutes), during the six procedures (3-21 minutes) and following cessation of procedures (21-36 minutes). Each data point represents the median particle concentration per size bin $\left(\# \mathrm{~cm}^{-3}\right)$ derived from $n=3$ replicates. The dotted lines indicate the lower reported size for a SARS-CoV-2 virus particle ( $50 \mathrm{~nm}$ diameter) 